\title{
AC 2010-1778: WHY ENGINEERING ECONOMY PROFESSORS SHOULD TEACH INTRODUCTORY CORPORATE FINANCE
}

\section{Ted Eschenbach, TGE Consulting}

Dr. Ted Eschenbach, P.E. is the principal of TGE Consulting, an emeritus professor of engineering management at the University of Alaska Anchorage, and the founding editor emeritus of the Engineering Management Journal. He is the author or coauthor of over 200 publications and presentations, including 13 books. With his coauthors he has won best paper awards at ASEM, ASCE, \& IIE conferences, and the 2009 Grant award for the best article in The Engineering Economist. He earned his B.S. from Purdue in 1971, his doctorate in industrial engineering from Stanford University in 1975, and his masters in civil engineering from UAA in 1999. 


\title{
Why Engineering Economy Professors Should Teach Introductory Corporate Finance
}

\begin{abstract}
Both engineering economy and finance focus their introductory courses on the time value of money. Yet, in spite of this shared foundation, those courses are very different. This paper discusses what these differences are, why they occur, and what the disciplines can offer each other. The goal is to help textbook authors and classroom teachers in each field to do a better job of learning from each other. This paper is written from the perspective of an engineering economist with over 30 years of teaching and textbook writing experience, who has recently had his world-view shifted by multiple forays into finance classrooms.
\end{abstract}

\section{Introduction}

The time value of money is the foundation of two fields-engineering economy and finance. Yet how those two fields are presented in their introductory course have a surprisingly small intersection. The basic reason is that engineering economy focuses at the project level, while introductory corporate finance focuses at the firm level. But both courses include the firm and project levels and both include applications of the time value of money to the personal lives of students. This creates the opportunity for an exchange of content, emphases, and approaches that can enrich the classrooms of both fields.

This paper analyzes the similarities and differences of typical engineering economy and finance (1) texts, (2) students, and (3) faculty. For example, most engineering economy texts will have chapters of detailed coverage with 20 -year projects that may have different cash flows in every year. In contrast, the typical project in a finance text has a five year life and uniform cash flows. The engineering students are on average better with mathematics, tables of factors, and spreadsheets, but the finance students analyze problems more quickly by using financial calculators.

The textbook authors and classroom teachers in each field have honed their presentations to match their students, their colleagues, and their course goals. Yet they have not done a good job of learning from each other. This paper suggests some mutual lessons. It is written from the perspective of an engineering economist with over 30 years of teaching and textbook writing experience, who has recently had his world-view shifted by multiple forays into finance classrooms.

The paper's organization starts with an overall comparison, which includes the comparison of exemplar textbooks. The next focus is the similarities between the two fields, which is followed by sections offering lessons first from finance for engineering economy and then vice versa. Appropriate references are included but there is no literature review, because other comparisons of the fields could not be found. The paper closes with a summary that suggests which lessons might offer the most opportunity for improvement in student understanding and capabilities. 
More so than most papers, this one comes with a caveat that some conclusions are based on personal observations and anecdotal evidence. The author would also like to apologize to the author of any engineering economy text that has either been omitted or inadvertently mischaracterized. While specific references are few, I have tried to include all of the larger players in the market of engineering economy texts in comparing the approaches of the two fields.

\section{The Overall Comparison of the Fields}

Table 1 summarizes some of the important differences in the fields, but a comparison of typical introductory texts is left for Table 2. One of the most important differences highlighted in Table 1 is the central role of finance for the careers of both business students and faculty. While engineering economy is often cited as one of the most important courses taken by engineering students who have transitioned to industry, it is not generally the focus of a career except for a very limited number of faculty.

One consequence of the difference in scale between the two fields is that our field is led by a single journal, The Engineering Economist, which includes pedagogy but focuses on research. There are many research journals in finance, and there is even a society, the Financial Education Association, with two journals devoted to finance education (Journal of Financial Education and Advances in Financial Education).

In terms of importance to the content of classes, a key difference is computational tools. Almost all engineering economy courses focus on using tabulated engineering economy factors, while many finance courses and texts focus on using financial calculators. The latter is clearly defensible, as significant amounts of business valuation of bonds, stocks, and simply described projects can be analyzed with financial calculators. The focus of engineering economy on the use of tabulated factors is less defensible. As Bill Peterson ${ }^{17}$ observed at the 2008 IIE conference in Miami, use of the tables rather than a spreadsheet by a practicing engineer is arguably evidence of incompetence that should cause counseling for a first offense and potentially job separation for repeat offenders.

Table 1. Summary of differences between engineering economy and finance

\begin{tabular}{|l|l|l|}
\hline & Engineering Economy & Finance \\
\hline Course focus & Project & Firm \\
\hline Students & & $\begin{array}{l}\text { Ranging from 1 course to } \\
\text { major \& focus of future job }\end{array}$ \\
\hline Degree of emphasis & One course or less & Low to moderate \\
\hline Principal computational tool & Tables \& spreadsheets & Financial calculator \\
\hline Faculty & 1 or 2 graduate courses & Major for 1 or 2 degrees \\
\hline Academic background in field & $\begin{array}{l}46 \% \text { of faculty teaching } \\
\text { engr. econ. report doing } \\
\text { research in engr. econ. (56\% } \\
\text { for IE \& 30\% for non-IE) }\end{array}$ & Focus on finance is a given \\
\hline Research background &
\end{tabular}


Selecting the engineering economy text ${ }^{14}$ for Table 2 was relatively easy-even though I would rather have selected my own text. (Note: before writing my own text, I had taught out of 6 different engineering economy texts - several in multiple editions, and I believe the chosen text is representative of our field.) Engineering Economic Analysis has been the market leading text for most of the decades since it was written by Don Newnan. I'd also like to note that the scale of Don's contribution to our field through this text is matched only by what I expect for long-term impact from his endowment of the best paper award for this division and for the career teaching award. Both will promote continuous improvement in how engineering economy is taught and thence applied.

The finance text ${ }^{1}$ in Table 2 was chosen because of the leading role Brigham plays in financial textbooks, because of this text's stature as a $14^{\text {th }}$ edition, and because I wanted the familiarity that comes from teaching out of a text. Note: this text was selected not by me (the emeritusadjunct) but by the assistant professor teaching the other sections. These observations are consistent with my experiences with two other finance texts ${ }^{11,18}$ that I have taught out of and others that I have examined. Note that $39 \%$ of the finance faculty used some form of a Brigham textbook and $33 \%$ used some form of Ross, Westerfield, and Jordan. ${ }^{8}$

Table 2. Comparison of example texts

\begin{tabular}{|c|c|c|}
\hline & Engineering Economy $^{14}$ & Finance $^{1}$ \\
\hline $\begin{array}{l}\text { Text length, revision cycle, \# } \\
\text { colors, list price }\end{array}$ & $\begin{array}{l}636 \text { pages, } 3 \text { years, } 2 \text {-color, } \\
\$ 110\end{array}$ & $\begin{array}{l}857 \text { pages, } 3 \text { years, } 4 \text {-color, } \\
\$ 214\end{array}$ \\
\hline $\begin{array}{l}\text { Average number per chapter of } \\
\text { End-of-chapter problems } \\
\text { Figures } \\
\text { Tables }\end{array}$ & $\begin{array}{r}57.5 \\
5.5 \\
1.5\end{array}$ & $\begin{array}{l}22.4 \text { (also } 11.4 \text { questions) } \\
4.2 \\
3.2\end{array}$ \\
\hline Chapters on interest rate & Ch. 15 Selecting MARR & $\begin{array}{l}\text { Ch. } 5 \text { Interest rates } \\
\text { Ch. } 8 \text { Risk \& rates of return } \\
\text { Ch. } 11 \text { Cost of capital }\end{array}$ \\
\hline Chapters on project analysis & Ch. $5-8,10,12,13,16$ & Ch. 10 Project cash flows \\
\hline Text chapters often skipped & Ch. 10 Uncertainty & $\begin{array}{l}\text { Ch. } 14 \text { Working capital } \\
\text { Ch. } 15 \text { Short-term assets } \\
\text { Ch. } 16 \text { Short-term liabilities } \\
\text { Ch. } 17 \text { Planning \& control } \\
\text { Ch. } 18 \text { Corporate } \\
\text { restructuring }\end{array}$ \\
\hline Pages of interest rate tables & 32 & $\begin{array}{l}0^{1} \\
8^{18}\end{array}$ \\
\hline
\end{tabular}

The exemplar finance text is topically more comprehensive than the exemplar engineering economy text, however the engineering economy text has much more detailed models of what are the economics of an engineering project. The larger number of problems for the engineering economy text suggests that more problems are likely to be assigned, which matches the conventional wisdom on engineering and business courses. 
While only anecdotal, comparing my past course assignment lists for engineering economy and finance show an average of 10.5 problems per week in engineering economy vs. 5.4 problems in finance. In general, I assign and collect slightly more homework than the average professor in engineering at my university. However, I assign and collect MUCH more homework than the average professor in business at my university.

The topic of depreciation is an interesting example of the dichotomy between finance and engineering economy. All engineering economy texts cover both MACRS and historical methods of depreciation, and surveys indicate that most faculty cover both in detail. Much to my surprise, MACRS was appendix material in my finance text. And to my astonishment, $63 \%$ of the students in my finance course had not been exposed to MACRS in either of the two prerequisite accounting courses. Obviously for accurate models of after-tax project cash flows, MACRS is required material.

\section{Similarities between Engineering Economy and Finance}

The focus of this paper is the differences between the two fields, and thus the mutual lessons that they can offer. However, it is also useful to examine the similarities between the two fields.

- Comparing texts within each field shows a high degree of commonality of topics ${ }^{4}$. The differences are principally sequencing and depth of coverage for particular topics. This similarity extends to "conventional wisdom" on particular topics, such as IRR within finance texts and EAW within engineering economy texts.

- While not consistent across all texts, each field seems to exhibit a slight tendency to slim texts down. This could be focused on reducing costs, better matching text coverage to average course coverage, or perhaps even conjectured declines in average levels of student preparation and capabilities.

- While most engineering economy texts clearly include spreadsheets as an integral part, they also clearly focus on tables over spreadsheets. Spreadsheets are part of most engineering economy courses (about $75 \%$ by 1998) ${ }^{12}$. Similarly, the finance texts include spreadsheets, but financial calculators are the principally used tool. However $53 \%$ of the faculty also use spreadsheets in the undergraduate course. ${ }^{8}$ While spreadsheets are part of teaching in both fields, they are not generally the dominant approach.

- While mentioned in some unknown fraction of the major texts, it seems inescapably clear that faculty recognize the pervasiveness of penetration by spreadsheets into future use by students.

- Both courses are typically delivered as lectures and grading relies heavily on in-class exams $^{4,12}$.

- Both fields rely on a very international group of faculty-particularly for junior faculty. This may have potential implications for the balance between an academic and a more practice-focused approach for teaching.

- Both fields have a disproportionate number of male faculty (particularly at the senior ranks). Better data is available for engineering as a whole than for engineering economy, but the numbers are likely to be similar. Women represent $12.3 \%$ of the engineering faculty but are concentrated in the lower ranks (20.7\% at the assistant, $14.1 \%$ at the associate, and $7.4 \%$ at the full level). ${ }^{7}$ A 2001 survey of finance faculty ${ }^{19}$ showed about $20 \%$ of the faculty were female, but the ratio varied from 1 in 3 at the assistant professor 
level, to 1 in 4 at the associate level, and to 1 in 17 at the full level. A 2008 update $^{8}$ did not show a significant change.

\section{Lessons from Finance}

Let us start with a simple list of some of the "lessons" to be learned.

- A common structure for valuing bonds, stocks, projects, \& firms helps students develop understanding.

- The use of calculators is matched to many of the simplified problems for which engineers use tables. Using such calculators allows students to solve many more problems.

- More complicated problems that involve gradients seem more likely to involve geometric gradients and spreadsheets.

- The valuing of bonds and stocks is also the foundation for personal investing by students.

- At a macro level risk is fundamental, cannot be avoided, and must be included for decision making.

- The capital asset pricing model (CAPM) and the security market line (even with problems in statistical validation) are central to the business community's view of the link between risk and reward.

- A clear view that equivalent annual worth (if mentioned at all) is fundamentally for mutually exclusive alternatives, which receive much less attention than independent projects.

- Financial options may be omitted, placed as a late chapter, or placed on a CD only chapter. Real options are included in about half of the texts checked (5 of 11), generally in longer texts not Essentials. This may offer a lesson for engineering economy texts, ${ }^{3,9}$ 16,20 that seem to be seeing some pressure to add financial and real option material ${ }^{13}$.

- The finance text's reliance on simple projects with uniform cash flows and 5 year horizons contains an implicit message to me that projects that require longer lives to be economically justified are likely to face challenges in garnering executive support. This may suggest that the many engineering economy examples that require a 20 year life may not be realistic for much of industry, although clearly more justified in a public agency context. This conclusion has been confirmed by two engineering economy professors (Bill Peterson and Neal Lewis) with long previous careers in industry.

In looking at the above list, one of the key questions is what challenges are linked with implementing these potential improvements. While the implications of the financial options bullet are clear, use of calculators is not. Many of the scientific calculators that engineering students use have the ability to do TVM (Time value of money calculations with PV, i, N, PMT, \& FV or equivalent keys). For example, many TI graphing models have the TVM buttons in a menu, and the programmable HP33s and 35s include the program in Chapter 17 of their manuals. However, it seems likely that relatively few of the engineering students and perhaps even fewer of the faculty in their engineering economy courses are familiar with and use these capabilities.

Also given the speed advantage of the calculators over the tables some students might be willing to spend $\$ 30$ to $\$ 40$ to buy a financial calculator. It is also worth noting that the HP $33 \mathrm{~s}$ and $35 \mathrm{~s}$ are allowed for use on the FE exam. 
On the other hand, the use of geometric gradients and spreadsheets for more realistic problems in finance courses can be used as a basis to question all of the effort expended in engineering economy on the financial arithmetic for tabulated factors of arithmetic gradients. Is the topic included to show how clever engineering economists can be or to assist students in their future careers?

If engineering economy courses do not include personal investing, and perhaps even if they do, the implications of the security market line (see Figure 1) for stock pricing and for the approval of engineering economy projects may not be clear. About half of the leading engineering economy texts $2,3,16,20$ cover the capital asset pricing model. Yet it is clear that this model is part of the approach of finance professionals to the valuation of all financial investments including stocks and engineering projects. How many texts, courses, and engineering economists tell students to know the $\beta$ for their firm? Then ask, "Is this project riskier than average for this firm, how much of the risk is systematic versus non-systematic, and how much should the required rate of return be adjusted?"

Figure 1. $\beta$ and the security market line.

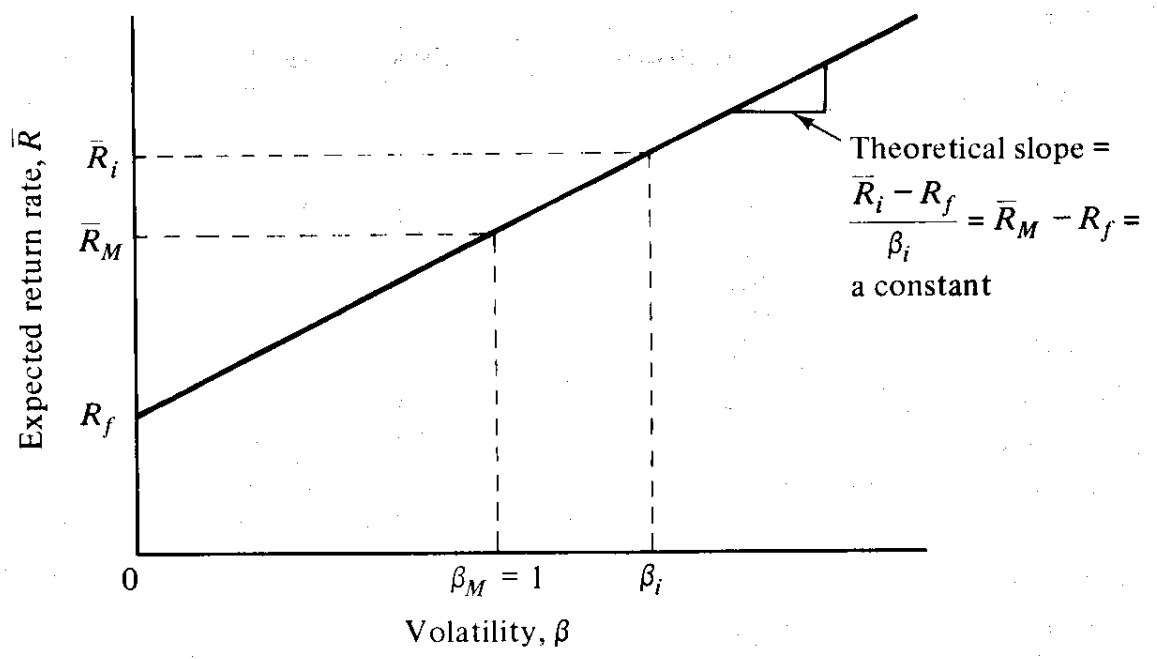

Even after authoring several engineering economy texts and taking at least one capital budgeting and finance course, I'll confess that I did not understand until I taught introductory finance the central role of systematic versus non-systematic risk. Note for those who are also unclear, in theory the non-systematic risk of a project should play at most a small role for firms and no role for diversified investors, versus the fraction that is systematic risk potentially linked with a firm's $\beta$. However that said, I'll confess to befuddlement as to how to in general separate a project's total risk into systematic and non-systematic pieces.

Of course, for the many engineering economy courses that skip their text's single chapter on uncertainty, the question of risk is much more likely to be handled qualitatively. Given the greater mathematical ability of the average engineering student, this would seem be an opportunity for improvement in at least some engineering economy courses. 
If personal investing and TVM functions for financial or scientific calculators are part of an engineering economy course, then modeling of bonds, stocks, and simple project models are mutually reinforcing topics where students can solve large numbers of problems in class and on their own. This is clearly supportive of an intuitive and complete understanding by students, which can be developed further through more realistic spreadsheet models for the greater detail associated with engineering projects.

\section{Lessons from Engineering Economy}

Like the last section, let us start with a simple bullet list of the lessons.

- Real project evaluations often require a long-term view (not 5 years) and estimation of non-uniform cash flows.

- PW and IRR have the same reinvestment assumptions.

- Challenger/defender is the correct response to the "Fisher intersection" problem for IRR or benefit/cost ratio, rather than saying IRR and benefit/cost are fundamentally flawed and incorrect measures.

- The double-root problem for IRR can be treated as an advanced topic that many intro courses omit (appendix not in main flow of text). This is clearly preferable to the silly examples included within some finance texts. No real mine is opened with a $\$ 150 \mathrm{M}$ investment at time 0 , shows a profit of $\$ 300 \mathrm{M}$ in year 1 , and is cleaned up for $\$ 160 \mathrm{M}$ in year 2.

As an engineering economist teaching finance, one of my biggest frustrations has been topics where the text for my course (and other finance texts) are stating a "conventional wisdom" that is wrong. The last 3 bullets are all items that every engineering economy text gets right, and all of the finance texts that I've examined get wrong!

\section{Factor Tables, Spreadsheets, and Exams}

Because of their importance to text and course design and of their central pedagogical role, it is worthwhile to look further at the issues in choosing the right balance between factor tables, financial calculators, and spreadsheets.

Since using a financial calculator requires exactly the same intuitive understanding as using the tables (except for $G$ ), the chief justification for using the tables instead seems to focus on exams in the course and the FE exam. Obviously using spreadsheets can represent a challenge for inclass testing, and they will not be permitted in the foreseeable future on the FE.

One challenge in looking at the engineering economy course is that it is multiple courses for different majors at some schools, required for some majors at some schools, and elective for other majors at other schools. Thus, in spite of decades of textbook authoring, Table 3 is the first time this author has seen estimates of each major taking the course considered on a national basis. Table 3 uses survey course data and national enrollment data to estimate the fraction of key engineering majors that take the engineering economy course. More definitive data would be useful in designing courses, texts, and potentially the FE exam. 
Table 3. Student majors and the engineering economy course

\begin{tabular}{|l|l|l|l|l|l|l|l|}
\hline & IE & CE & ChemE & EE & ME & $\begin{array}{l}\text { Other } \\
\text { Engr. }\end{array}$ & Other \\
\hline $\begin{array}{l}\text { Student } \\
\text { distribution }^{12}\end{array}$ & $18 \%$ & $19 \%$ & $7 \%$ & $15 \%$ & $22 \%$ & $12 \%$ & $7 \%$ \\
\hline $\begin{array}{l}\text { National degree } \\
\text { split }^{7}\end{array}$ & $4.5 \%$ & $13.7 \%$ & $6.5 \%$ & $14.5 \%$ & $23.4 \%$ & $62.6 \%$ & \\
\hline $\begin{array}{l}\text { Estimated fraction } \\
\text { taking }^{*}\end{array}$ & $100 \%$ & $35.1 \%$ & $27.0 \%$ & $26.0 \%$ & $23.8 \%$ & $4.8 \%$ & \\
\hline
\end{tabular}

These results assume that all IE's take the course, and then calculates what fraction of each major takes the course to give the split in students majors in Figure 1 of $^{12}$. This calculation also removes the $7 \%$ of other majors. The results depend on the accuracy of the split in student majors and could be distorted by different classifications of majors and by trends between the survey date and $2007-2008$.

As detailed in Table 4 engineering economy is $8 \%$ of the morning section of the FE exam, but it is not included for the afternoon sections of the mechanical and electrical exams based on the exam specification listed in the supplied reference material. Obviously, some students choose the general exam over "their major" exam, and those students average about $9 \%$ of the total FE on engineering economy. For all but IE's the average is only 4 to $6 \%$.

Table 4. Engineering economy and the FE exam

\begin{tabular}{|l|l|l|l|l|l|l|l|}
\hline & IE & CE & ChemE & Env E & EE & ME & General \\
\hline Morning & $8 \%$ & $8 \%$ & $8 \%$ & $8 \%$ & $8 \%$ & $8 \%$ & $8 \%$ \\
\hline Afternoon & $15 \%$ & $<2 \%$ & $2 \%$ & 0 & 0 & 0 & $10 \%$ \\
\hline
\end{tabular}

A key question is whether it is appropriate to use the FE exam to justify a table based approach to engineering economy when the subject represents $4 \%$ to $12 \%$ of the FE exam which many engineering students do not take. Thus, I suggest that tables may need to be a small part of engineering economy courses, but that part should be as small as possible $\left(\mathrm{see}^{5}\right.$ for a more detailed discussion of this).

Another reason to consider relying on TVM calculators in engineering economy courses is the improvement in accuracy for student work on homework and exams. Paul Componation of the University of Alabama in Huntsville has been tracking student errors on exams for many years. He has found a consistent level of $30 \%$ of the student errors represent transposed digits or table lookup errors of wrong row, column, or page 5 . Note that this error rate has remained "constant" for short and long exams, for short and long problems, and even for exams where students could not turn it in before the period ended. These arithmetic errors are related to the number of items that must be entered in the calculator, so use of TVM calculators should reduce the number of errors. Students will still sometimes enter incorrect values, but if doing more problems has improved their understanding, we can hope that they'll be more likely to catch some of the errors.

Financial calculators and spreadsheets are simpler to use, often more intuitive, and much more likely to be used after graduation than the tables. I know I would rather spend less time on interpolation for $i$ or $N$, while being able to use an APR of 6.5\% for a 30-year mortgage for a 2 minute quiz. Calculators and spreadsheets should play a larger role in the "average" engineering 
economy course. Our chief concern should be helping students use this material in the real world rather than on academic exams and the transitional exam from learning to the real world.

\section{Summary and Conclusions}

As the title of this paper suggests, I believe experienced professors of engineering economy have the opportunity to improve their courses by teaching the time value of money from another perspective. I hope that this paper can help those who won't have the opportunity to do so, and perhaps provide a head start for those that can.

I know that the next time I teach engineering economy, I'll be

- Having students use financial calculators or equivalent TVM capabilities on their engineering calculators,

- Covering risk differently,

- Skipping or minimizing my coverage of arithmetic gradients,

- Using bonds, stocks, and projects for a unified conceptual approach to evaluation that students can link to their future lives, and

- Relying on spreadsheets even more.

For those that want to change their engineering economy course to include financial calculators, the next editions of two engineering economy texts will include an appendix on TVM

calculators, including ones that can be used on the FE exam ${ }^{6,15}$. This material will allow students on their own or classes led by their instructors to do more problems, with more correct answers, and the same conceptual understanding.

While I believe it is too demanding for the undergraduate course (at least at my university), for those who want to examine finance texts for lessons to be learned, I recommend a text by an author who started in industry, became an adjunct, and then wrote a text ${ }^{10}$.

\section{Acknowledgements}

I could not have written this paper without years of helpful suggestions from the community of engineering economy faculty, and more recent help from my colleagues in finance at UAA. Four colleagues in particular have helped with the specific ideas in this paper: Paul Componation of the University of Alabama in Huntsville, Jerome Lavelle of North Carolina State University, Neal Lewis of the University of Bridgeport, and William Peterson of Minnesota State University, Mankato.

\section{References}

1. Besley, Scott, and Eugene F. Brigham, Essentials of Managerial Finance 14 ${ }^{\text {th }}$, South-Western, 2008.

2. Blank, Leland T., and Anthony J. Tarquin, Engineering Economy $6^{\text {th }}$, McGraw Hill, 2005.

3. Canada, John R., William G. Sullivan, Dennis J. Kulonda, and John A. White, Capital Investment Analysis $3^{\text {rd }}$, Prentice Hall, 2005. 
4. Cooley, Philip L., and J. Louis Heck, "Establishing Benchmarks for Teaching the Undergraduate Introductory Course in Financial Management," Journal of Financial Education, Vol. 22, Fall 1996, pp. 1-10.

5. Eschenbach, Ted G., and Neal A. Lewis, "Calculators vs. Factor Tables and Reducing the Financial Arithmetic," Proceedings of the 2010 IERC National Conference, Cancun, June 2010, CD (submitted).

6. Eschenbach, Ted G., Engineering Economy: Applying Theory to Practice $3^{\text {rd }}$, Oxford University Press, 2011 (in press).

7. Gibbons, Michael T., "Engineering by the Numbers," American Society for Engineering Education, from Profiles of Engineering and Engineering Technology Colleges, 2009.

8. Hamilton, Janet, and Kent T. Saunders, “An Update of Teaching Methods and Evaluation in the Introductory Finance Classroom," Advances in Financial Education, Vol. 7, Summer \& Winter 2009, pp. 86-100.

9. Hartman, Joseph C., Engineering Economy and the Decision-Making Process, Prentice Hall, 2007.

10. Lasher, William R., Practical Financial Management $6^{\text {th }}$, South-Western, 2011.

11. Megginson, William L., and Scott B. Smart, Introduction to Corporate Finance, Thomson South-Western, 2006.

12. Needy, Kim LaScola, Heather Nachtmann, Jerome P. Lavelle, and Ted G. Eschenbach, "An Empirical Analysis of Engineering Economy Pedagogy,” The Engineering Economist, Vol. 45 No. 1, 2000, pp. 74-92.

13. Nachtmann, Heather, Kim LaScola Needy, Jerome P. Lavelle, and Ted G. Eschenbach, "How Do Engineering Managers Teach Engineering Economy?" Proceedings of the 2008 ASEM National Conference, West Point, November 2008, CD.

14. Newnan, Donald G., Jerome P. Lavelle, and Ted G. Eschenbach, Engineering Economic Analysis 10 ${ }^{\text {th }}$, Oxford University Press, 2009.

15. Newnan, Donald G., Ted G. Eschenbach, and Jerome P. Lavelle, Engineering Economic Analysis $11^{\text {th }}$, Oxford University Press, 2012 (in press).

16. Park, Chan S. Contemporary Engineering Economic Analysis, $4^{\text {th }}$, Prentice Hall, 2007.

17. Peterson, William R., "Spreadsheets as the Primary Means of Engineering Economy Education," Proceedings of the 2009 IERC National Conference, Miami, June 2010, abstract on CD.

18. Ross, Stephen A., Randolph W. Westerfield, and Bradford D. Jordan, Essentials of Corporate Finance $6^{\text {th }}$, McGraw-Hill, 2008.

19. Saunders, Kent T., "Teaching Methods and Assessment Techniques for the Undergraduate Introductory Finance Course: A National Survey," Journal of Applied Finance, Vol. 11, No. 1, Fall 2001, pp. 110-112, (unabridged version accessed at http://facultyweb.anderson.edu as saundersfpe.doc March 1, 2001)

20. Sullivan, William G., Elin M. Wicks, and C. Patrick Koelling, Engineering Economy $14^{\text {th }}$, Pearson Prentice Hall, 2009. 